\title{
Blended Learning dan E-Learning Berbasis Edmodo Dalam Peningkatan Motivasi Belajar Matematika
}

\author{
${ }^{1}$ Dayu Citra Wahyuni, ${ }^{2}$ Iip Sugiharta \\ 1,2 Pendidikan Matematika, Universitas Islam Negeri Raden Intan Lampung \\ Jl. Letnan Kolonel H. Endro Suratmin, Sukarane, Lampung, Indonesia \\ E-mail: ${ }^{1}$ dayucitrawahyuni99@gmail.com
}

Article History:

Received: 03-12-2018; Received in revised form: 26-01-2019; Accepted: 04-02-2019;

Available online: 12-03-2019

\begin{abstract}
This study aims to determine the increase in motivation to learn mathematics in junior high school by using blended learning and edmodo-based e-learning. The research method used was quasi-experimental, with a sample of 86 students divided into three classes, namely blended learning class, e-learning class, and conventional class. The results of the questionnaire were carried out statistical tests using a one-way ANOVA test and further tests using the Scheffe test to determine the differences in the increase in motivation to learn mathematics in each experimental class. Thus, it can be concluded that $\boldsymbol{H}_{1}$ is accepted which states that there is an increase in motivation to learn mathematics in junior high school by using edmodo-based blended learning and e-learning.
\end{abstract}

Keywords: Blended Learning; e-learning; Edmodo; Motivation to Learn; Mathematics

\begin{abstract}
Abstrak
Penelitian ini bertujuan untuk mengetahui peningkatan motivasi belajar matematika di SMP dengan menggunakan blended learning dan e-learning berbasis edmodo. Metode penelitian yang digunakan adalah quasi eksperimen, dengan sampel sebanyak 86 peserta didik yang terbagi menjadi tiga kelas, yaitu kelas blended learning, kelas e-learning, dan kelas konvensional. Hasil dari angket tersebut dilakukan uji statistik menggunakan uji ANOVA satu arah dan uji lanjut dengan menggunakan uji scheffe untuk mengetahui perbedaan peningkatan motivasi belajar matematika pada masing-masing kelas eksperimen. Sehingga, dapat disimpulkan bahwa $\boldsymbol{H}_{\mathbf{1}}$ diterima yang menyatakan bahwa terdapat peningkatan motivasi belajar matematika di SMP dengan menggunakan blended learning dan e-learning berbasis edmodo.
\end{abstract}

Kata Kunci: Blended Learning; e-learning; Edmodo; Motivasi Belajar; Matematika 


\section{Pendahuluan}

Pendidikan merupakan kebutuhan manusia yang paling utama, bertujuan untuk memperoleh ilmu pengetahuan serta dapat memiliki budi pekerti yang baik ${ }^{1}$. Pendidikan diharapkan dapat menghasilkan manusia yang berkualitas dengan mengembangkan potensi secara inovatif dan kreatif sehingga mampu bersaing di era global saat ini ${ }^{2}$. Allah SWT sangat mencintai orang-orang yang berilmu, sebagaimana yang dijelaskan dalam Al-Qur'an surah Al-Mujadilah ayat 11:

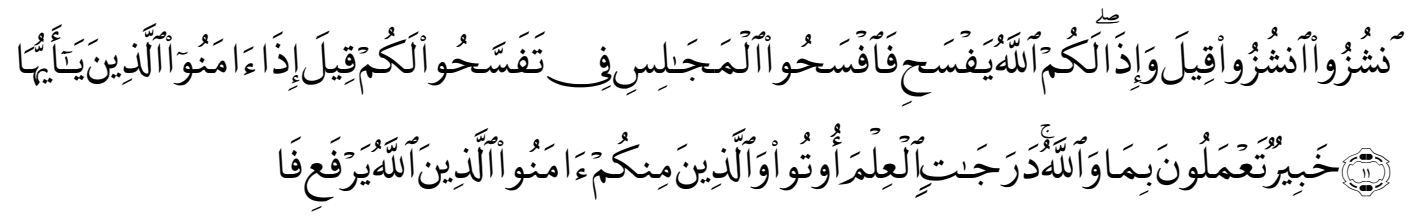

Artinya :

"Hai orang-orang beriman apabila kamu dikatakan kepadamu: "Berlapang-lapanglah dalam majlis", Maka lapangkanlah niscaya Allah akan memberi kelapangan untukmu. dan apabila dikatakan: "Berdirilah kamu", Maka berdirilah, niscaya Allah akan meninggikan orang-orang yang beriman di antaramu dan orang-orang yang diberi ilmu pengetahuan beberapa derajat. dan Allah Maha mengetahui apa yang kamu kerjakan ${ }^{3}$

Firman Allah SWT dalam Al-Qur'an surah Al-Mujadilah ayat 11 menerangkan bahwa Allah SWT akan meninggikan derajat kepada orangorang yang beriman dan berilmu pengetahuan. Ilmu pengetahuan berperan dalam upaya meningkatkan kualitas individu. Kualitas individu dapat ditingkatkan melalui proses pembelajaran. Pembelajaran bertujuan untuk mengembangkan kemampuan dari peserta didik ${ }^{4}$.

Pada kenyataannya, tujuan tersebut belum tercapai secara optimal karena masih banyak peserta didik yang mengalami kesulitan khususnya dalam pelajaran matematika ${ }^{5}$. Matematika tergolong sebagai pelajaran umum yang terdapat pada semua jenjang pendidikan'6.

${ }^{1}$ Bettri Yustinaningrum, "The Implementation of E-Learning Web-Based Model Centric Course (Edmodo) toward The Mathematics' Interest and Learning Outcomes," Al-Jabar: Jurnal Pendidikan Matematika 9, no. 1 (2018): 25.

2Elis Mediawati, "Pengaruh Motivasi Belajar Mahasiswa Dan Kompetensi Dosen Terhadap Prestasi Belajar," Jurnal Pendidikan Ekonomi Dinamika Pendidikan 5, no. 2 (2010): 369.

${ }^{3}$ Departemen Agama RI, AI-Qur'an Dan Terjemahnya (Bandung, 2008).

${ }^{4}$ Siti Suprihatin, "Upaya Guru Dalam Meningkatkan Motivasi Belajar Siswa," Jurnal Pendidikan Ekonomi UM Metro 3, no. 1 (2015): 73.

5I Wayan Sumandya, I Gusti Putu Suharta, and Gede Suweken, "Pengembangan Pembelajaran Geometri Dimensi Tiga Berwawasan Pendidikan Matematika Realistik Berorientasi Blended Learning Dalam Upaya Meningkatkan Aktivitas Dan Hasil Belajar 


\section{Blended Learning dan E-Learning...}

Berdasarkan penyebaran angket peserta didik terkait dengan motivasi belajar kepada 30 peserta didik di SMP N 2 Kalianda pada pelajaran matematika, diperoleh data dari beberapa pertanyaan.

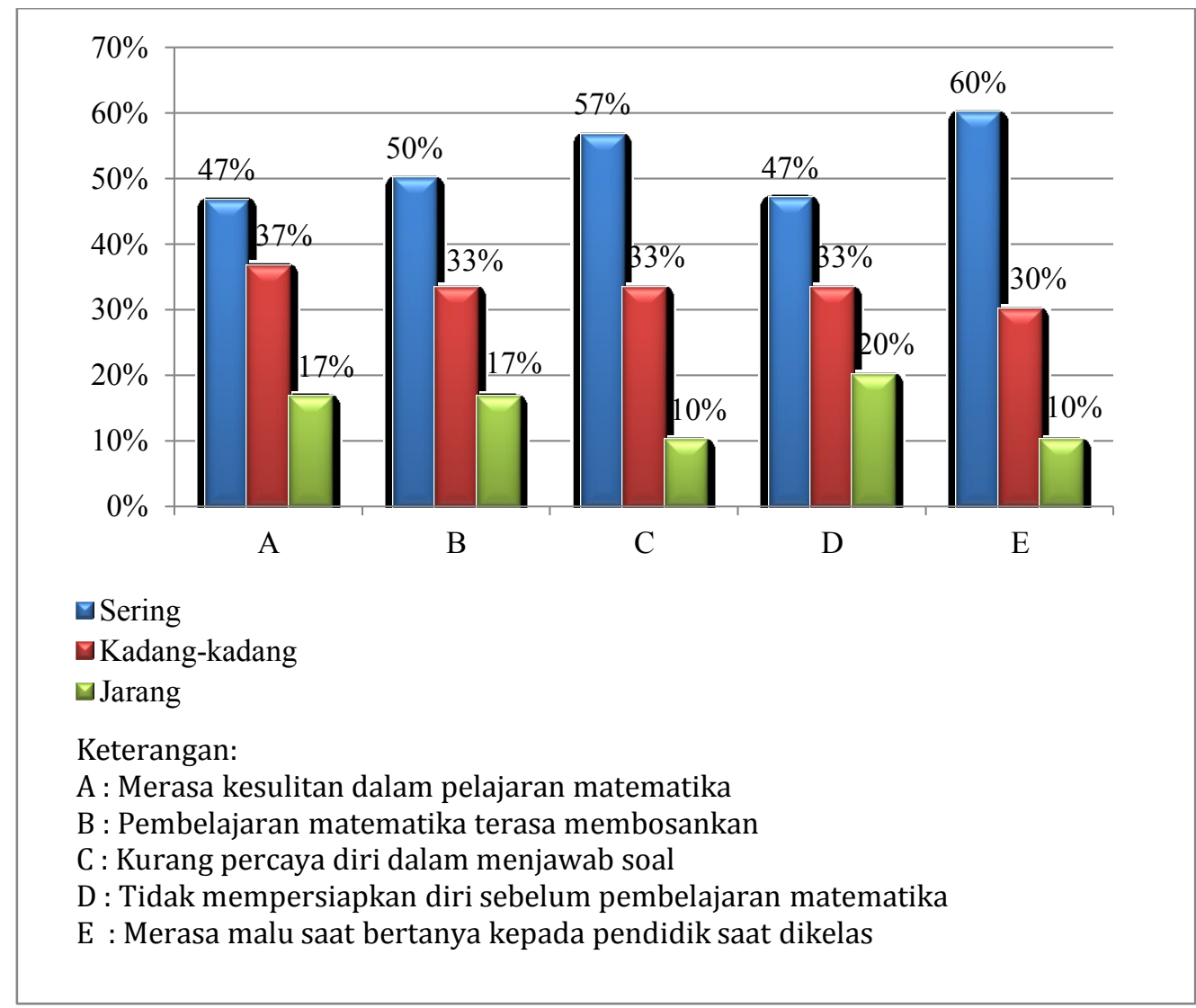

Gambar 1. Diagram Hasil Angket Motivasi Belajar

Berkenaan dengan Gambar 1, diketahui bahwa motivasi belajar matematika peserta didik SMP Negeri 2 Kalianda masih rendah disebabkan karena peserta didik merasa kesulitan dalam pelajaran matematika, kejenuhan peserta didik saat pembelajaran matematika, kurangnya kepercayaan diri peserta didik dalam menjawab soal matematika yang diberikan oleh pendidik, peserta didik tidak mempelajari materi sebelum pembelajaran matematika dimulai, dan peserta didik merasa malu untuk bertanya kepada pendidik di dalam kelas.

Mayoritas peserta didik sudah mempunyai perangkat lunak yang diimbangi dengan potensi yang ada disekolah seperti jaringan wifi dan lab komputer sehingga dapat dimanfaatkan dalam pembelajaran, sedangkan

Matematika Siswa Kelas XI SMK," E-Journal Program Pascasarjana Universitas Pendidikan Ganesha Program Studi Matematika 2 (2013).

${ }^{6}$ Edi Prayitno and Lusi Rachmiazasi Masduki, "Pengembangan Media Blended Learning Dengan Model Flipped Classroom Pada Mata Kuliah Pendidikan Matematika II," Jurnal IImiah Pendidikan Matematika 1, no. 2 (n.d.): 121. 
peserta didik belum diarahkan pada pemanfaatan fasilitas sebagai media pembelajaran7. Model pembelajaran yang dapat memanfaatkan perkembangan teknologi yang ada saat ini diperlukan agar motivasi belajar matematika peserta didik meningkat ${ }^{8}$.

Penelitian yang dilakukan oleh Pei-Di Shen dan Chia-Wen Tsai diperoleh bahwa siswa di SRL dan BL kelompok dengan kelas online memiliki nilai tertinggi menggunakan DBMS antara empat kelompok. Siswa yang menerima perawatan web-enabled SRL juga mengungguli kelompok kontrol yang tidak memiliki manfaat utama di SRL ${ }^{9}$.

Penelitian yang dilakukan oleh Maurice Taylor, Sait Atas, dan Shehzad Ghani diperoleh bahwa mahasiswa pascasarjana memiliki pembelajaran khusus persyaratan yang mengharuskan perhatian pada aspek-aspek tertentu dari metode pengajaran dan profesor yang mengajar dalam format pembelajaran blended learning bekerja untuk memenuhi kebutuhan siswa tersebut ${ }^{10}$.

Penelitian yang dilakukan oleh Rex P. Bringula, John Nikko Alvarez, Maron Angelo Evangelista, dan Richard B. So, pengujian perbedaan antara sarana menegaskan bahwa perbedaan antara skor posttest dan pretest signifikan. sebagian besar keahlian berkolerasi dengan waktu yang digunakan dalam memecahkan permasalahan linear. Selain itu, mengidentifikasi ekspresi matematika yang setara diperlukan semua tiga bentuk interaksi pelajar, bagi siswa untuk menjadi akrab dengan keterampilan ini11.

Berdasarkan penelitian yang telah dilakukan oleh John Marco Pima, dkk yang bertujuan untuk memberikan kontribusi terhadap pemahaman dan pengetahuan tentang tren penelitian saat ini blended learning dan memastikan banyak yang perlu dilakukan dalam ketentuan kerangka kerja blended learningi2.

${ }^{7}$ Dharmawati, "Penggunaan Media E-Learning Berbasis Edmodo Dalam Pembelajaran English for Business," Jurnal Sistem Informasi 01, no. 01 (2017): 43.

8Yunika Lestaria Ningsih, Marhamah, and Misdalina, "Peningkatan Hasil Belajar Dan Kemandirian Belajar Metode Statistika Melalui Pembelajaran Blended Learning," Al-Jabar: Jurnal Pendidikan Matematika 8, no. 2 (2017): 156.

${ }^{9}$ Pei-Di Shen and Chia-Wen Tsai, "Exploring the Effects of Web-Enabled Self-Regulated Learning and Online Class Frequency on Students' Computing Skills in Blended Learning Courses," International Journal of Mobile and Blended Learning 1, no. 3 (2009): 1.

${ }^{10}$ Maurice Taylor, Sait Atas, and Shehzad Ghani, "Exploring the Experiences of Students and Professors in a Blended Learning Graduate Program: A Case Study of a Faculty of Education," International Journal of Mobile and Blended Learning 9, no. 1 (2017): 1.

${ }^{11}$ Rex P. Bringula et al., "Learner-Interface Interactions with Mobile- Assisted Learning in Mathematics: Effects on and Relationship with Mathematics Performance," International Journal of Mobile and Blended Learning 9, no. 1 (2017): 34.

${ }^{12} J o h n$ Marco Pima et al., "A Thematic Review of Blended Learning in Higher Education," International Journal of Mobile and Blended Learning 10, no. 1 (2018): 1. 
Penelitian yang telah dilakukan oleh Diego Casanova dan Antonio Moreira yang bertujuan menyediakan kerangka kerja untuk guru dalam pendidikan tinggi untuk mencerminkan dan mendiskusikan mutu pembelajaran Technology-Enhanced di program blended learning mereka ${ }^{13}$.

Motivasi ialah suatu dorongan yang berasal dari dalam diri peserta $\operatorname{didik}^{14}$. Kenyataan yang sering terjadi saat ini, peserta didik tidak aktif dalam pembelajaran matematika dan peserta didik kesulitan dalam mengingat materi yang baru saja disampaikan. Faktor yang menyebabkan permasalahan tersebut terjadi yaitu kurangnya motivasi belajar matematika peserta didik, kurangnya antusias peserta didik dalam belajar matematika, dan peserta didik tidak mempersiapkan diri sebelum menerima pembelajaran matematika, serta penggunaan model pembelajaran matematika yang kurang tepat ${ }^{15}$. E-Learning merupakan salah satu model pembelajaran yang memanfaatkan teknologi informasi, sedangkan Blended Learning merupakan model pembelajaran yang menggabungkan antara pembelajaran online dan pembelajaran tatapmuka. Edmodo merupakan media pembelajaran berbasis teknologi.

Berdasarkan masalah tersebut, peneliti merasa perlu melakukan penelitian yang lebih mendalam untuk mengetahui adakah peningkatan motivasi belajar matematika di SMP menggunakan blended learning dan elearning berbasis edmodo.

\section{Metode}

Metode yang digunakan yaitu quasi eksperimental design. SMP Negeri 2 Kalianda tahun pelajaran 2018/2019 menjadi populasi pada penelitian ini dengan jumlah seluruh peserta didik kelas XIII. Sampel dalam penelitian ini yaitu peserta didik kelas VIII A sebagai kelas eksperimen 1 dengan model blended learning, peserta didik kelas VIII B sebagai kelas eksperimen 2 dengan model e-learning dan peserta didik kelas VIII C sebagai kelas eksperimen 3 dengan model konvensional. Desain penelitian menggunakan pretest-posttest control group design.

${ }^{13}$ Diego Casanova and Antonio Moreira, "A Model for Discussing the Quality of Technology-Enhanced Learning in Blended Learning Programmes," International Journal of Mobile and Blended Learning 9, no. 4 (2017): 1.

${ }^{14}$ Agus Setiawan, "Hubungan Kausal Penalaran Matematis Terhadap Prestasi Belajar Matematika Pada Materi Bangun Ruang Sisi Datar Ditinjau Dari Motivasi Belajar Matematika Siswa," Al-Jabar: Jurnal Pendidikan Matematika 7, no. 1 (2016): 94.

${ }^{15}$ Erny Untari, "Eksperimentasi Pembelajaran Kooperatif Tipe STAD Dan TPS Terhadap Prestasi Belajar Matematika Ditinjau Dari Motivasi Berprestasi," Al-Jabar: Jurnal Pendidikan Matematika 8, no. 1 (2017): 36. 
Tabel 1. Pretest-Posttest Control Group Design

\begin{tabular}{|l|c|c|c|}
\hline \multicolumn{1}{|c|}{ Grup } & Pretes & Perlakuan & Postes \\
\hline Blended learning & $\mathrm{O}_{1}$ & $\mathrm{X}_{1}$ & $\mathrm{O}_{2}$ \\
\hline E-learning & $\mathrm{O}_{3}$ & $\mathrm{X}_{2}$ & $\mathrm{O}_{4}$ \\
\hline Konvensional & $\mathrm{O}_{5}$ & $\mathrm{X}_{3}$ & $\mathrm{O}_{6}$ \\
\hline
\end{tabular}

Teknik pengumpulan data dalam penelitian ini menggunakan teknik observasi dan angket. Observasi yaitu mengumpulkan data dengan melakukan pengamatan dan mencatat secara sistematis terhadap sesuatu yang diselidiki. Angket yaitu sebuah daftar pertanyaan yang harus diisi oleh responden. Teknik analisis yang digunakan yaitu uji normalitas, uji homogenitas, uji hipotesis dengan menggunakan ANOVA satu arah dan uji lanjut dengan menggunkan uji scheffe.

\section{Motivasi Belajara Matematika, Blended Learning, dan E-Learning Berbasis Edmodo}

\section{Uji Normalitas}

Uji normalitas angket sebelum pada output Kolmogorov-Smirnov untuk kelas blended learning, kelas e-learning dan kelas konvensional adalah 0,200 ,0,085, dan 0,200 sedangkan. Karena nilai :Asymp.Sig $>\alpha$ maka ketiga data berdistribusi normal.

Tabel 2. Hasil Uji Normalitas Angket Sebelum

\begin{tabular}{|ll|c|c|c|c|c|c|}
\hline \multirow{2}{*}{} & \multicolumn{2}{|c|}{ Kelas } & \multicolumn{3}{|c|}{$\begin{array}{c}\text { Kolmogorov- } \\
\text { Smirnov }\end{array}$} & \multicolumn{3}{c|}{ Shapiro-Wilk } \\
\cline { 3 - 8 } & Statistic & df & Sig. & Statistic & df & Sig. \\
\hline Angket & Blended learning & .109 & 35 & $.200^{*}$ & .950 & 35 & .114 \\
Sebelum & E-learning & .139 & 35 & .085 & .924 & 35 & .019 \\
& Konvensional & .096 & 35 & $.200^{*}$ & .963 & 35 & .290 \\
\hline
\end{tabular}

Uji normalitas angket sesudah pada output Kolmogorov-Smirnov untuk kelas blended learning, kelas e-learning dan kelas konvensional adalah $0,2,0,055$, dan 0,2 sedangkan $\alpha=0,05$. Karena nilai : Asymp.Sig $>\alpha$ maka ketiga data berdistribusi normal. 


\section{Blended Learning dan E-Learning...}

Tabel 3. Hasil Uji Normalitas Angket Sesudah

\begin{tabular}{|r|c|c|c|c|c|c|}
\hline \multirow{2}{*}{ Kelas } & \multicolumn{3}{|c|}{ Kolmogorov-Smirnov } & \multicolumn{3}{|c|}{ Shapiro-Wilk } \\
\cline { 2 - 7 } & Statistic & $\mathrm{df}$ & Sig. & Statistic & df & Sig. \\
\hline Angket Sesudah Eksperimen 1 & .109 & 35 & $.200^{*}$ & .912 & 35 & .009 \\
Eksperimen 2 & .146 & 35 & .055 & .906 & 35 & .006 \\
Eksperimen 3 & .070 & 35 & $.200^{*}$ & .977 & 35 & .663 \\
\hline
\end{tabular}

\section{Uji Homogenitas}

Tabel 4. Hasil Uji Homogenitas Angket Sebelum

\begin{tabular}{|ll|c|c|c|c|}
\hline & Levene Statistic & df1 & df2 & Sig. \\
\hline Angket Sebelum & Based on Mean & 2.152 & 2 & 102 & .121 \\
& Based on Median & 1.573 & 2 & 102 & .212 \\
& Based on Median and & 1.573 & 2 & 98.967 & .213 \\
with adjusted df & & & & \\
Based on trimmed mean & 2.139 & 2 & 102 & .123 \\
\hline
\end{tabular}

Berdasarkan pada hasil diperoleh bahwa nilai sign $=0,121$ lebih dari 0,05 oleh karena itu nilai Asymp. sig. $>\alpha$ maka ketiga data homogen.

Tabel 5. Hasil Uji Homogenitas Angket Sesudah

\begin{tabular}{|cl|c|c|c|c|}
\hline & Levene Statistic & df1 & df2 & Sig. \\
\hline Motivasi & Based on Mean & 2.406 & 2 & 102 & .095 \\
Belajar & Based on Median & 2.288 & 2 & 102 & .107 \\
& Based on Median and with adjusted df & 2.288 & 2 & 101.033 & .107 \\
Based on trimmed mean & 2.404 & 2 & 102 & .095 \\
\hline
\end{tabular}

Berdasarkan pada hasil diperoleh bahwa nilai sign $=0,095$ lebih dari 0,05 oleh karena itu nilai Asymp. sig. $>\alpha$ maka ketiga data homogen.

\section{Uji ANOVA}

Tabel 6. Hasil Uji Hipotesis

ANOVA

\begin{tabular}{|l|c|c|c|c|c|}
\hline & Sum of Squares & df & Mean Square & F & Sig. \\
\hline Between Groups & 2052.400 & 2 & 1026.200 & 16.619 & .000 \\
Within Groups & 6298.457 & 102 & 61.750 & & \\
Total & 8350.857 & 104 & & & \\
\hline
\end{tabular}


Karena sig. $<\alpha$ atau $0,000<0,05$ sehingga $H_{1}$ diterima artinya terdapat peningkatkan motivasi belajar matematika di SMP dengan menggunakan blended learning dan e-learning berbasis edmodo. Karena $H_{1}$ diterima, maka dilakukan uji lanjut untuk mengetahui perbedaan antara masing-masing kelas eksperimen.

\section{Uji Lanjut}

Tabel 7. Hasil Uji Lanjut

\begin{tabular}{|c|c|c|c|c|c|c|}
\hline \multirow[b]{2}{*}{ (I) Kelas } & \multirow[b]{2}{*}{ (J) Kelas } & \multirow{2}{*}{$\begin{array}{c}\text { Mean } \\
\text { Difference (I- } \\
\text { J) }\end{array}$} & \multirow[b]{2}{*}{ Std. Error } & \multirow[b]{2}{*}{ Sig. } & \multicolumn{2}{|c|}{$\begin{array}{l}95 \% \text { Confidence } \\
\text { Interval }\end{array}$} \\
\hline & & & & & $\begin{array}{l}\text { Lower } \\
\text { Bound }\end{array}$ & $\begin{array}{l}\text { Upper } \\
\text { Bound }\end{array}$ \\
\hline \multirow[t]{2}{*}{ Blended learning } & E-learning & $7.74286^{*}$ & 1.87844 & .000 & 3.0766 & 12.4092 \\
\hline & Konvensional & $10.42857^{*}$ & 1.87844 & .000 & 5.7623 & 15.0949 \\
\hline \multirow[t]{2}{*}{ E-learning } & Blended learning & $-7.74286^{*}$ & 1.87844 & .000 & -12.4092 & -3.0766 \\
\hline & Konvensional & 2.68571 & 1.87844 & .363 & -1.9806 & 7.3520 \\
\hline \multirow[t]{2}{*}{ Konvensional } & Blended learning & $-10.42857^{*}$ & 1.87844 & .000 & -15.0949 & -5.7623 \\
\hline & E-learning & -2.68571 & 1.87844 & .363 & -7.3520 & 1.9806 \\
\hline
\end{tabular}

*. The mean difference is significant at the 0.05 level.

Berdasarkan hasil uji lanjut diperoleh bahwa terdapat perbedaan motivasi belajar pada kelas blended learning dengan kelas eksperimen yang lain, sedangkan kelas e-learning dan kelas konvensional tidak terdapat perbedaan dalam motivasi belajar peserta didik di SMP.

\section{Penutup}

\section{Simpulan}

Berdasarkan penelitian dan pembahasan yang telah dipaparkan, dapat diketahui bahwa motivasi belajar dengan menggunakan model blended learning lebih tinggi dibandingkan menggunakan model e-learning maupun model konvensional. Hal ini diperkuat dengan perolehan hasil perhitungan uji hipotesis dengan melalui uji ANOVA satu arah pada taraf signifikan 0.05 didapat hasil sig. $<\alpha$, sehingga $\mathrm{H}_{1}$ diterima yang artinya terdapat peningkatan motivasi belajar matematika di SMP dengan menggunakan blended learning dan e-learning berbasis edmodo.

Oleh karena itu, model pembelajaran blended learning mampu memberikan perubahan motivasi belajar bagi peserta didik dan model ini dapat digunakan pendidik dalam kegiatan pembelajaran guna menciptakan suasana pembelajaran baru. 
Saran

Berdasarkan pada kesimpulan dan pembahasan hasil penelitian yang telah dikemukakan, peneliti memberikan saran mengingat tersedianya fasilitas teknologi saat ini maka penerapan model pembelajaran blended learning dapat menjadi model pembelajaran di masa depan untuk meningkatkan motivasi belajar salah satunya pelajaran matematika, tidak menutup kemungkinan pelajaran lain pun dapat menggunakan model pembelajaran blended learning. Model pembelajaran blended learning juga diharapkan dapat diterapkan di semua jenjang pendidikan mulai dari pendidikan SD, SMP, SMA, maupun jenjang perkuliahan.

\section{Daftar Pustaka}

B. Uno, Hamzah. Teori Motivasi Dan Pengukurannya Analisis Di Bidang Pendidikan. Jakarta: PT Bumi Aksara, 2009.

Bringula, Rex P., John Nikko Alvarez, Maron Angelo Evangelista, and Richard B. So. "Learner-Interface Interactions with Mobile- Assisted Learning in Mathematics: Effects on and Relationship with Mathematics Performance." International Journal of Mobile and Blended Learning 9, no. 1 (2017).

Casanova, Diego, and Antonio Moreira. "A Model for Discussing the Quality of Technology-Enhanced Learning in Blended Learning Programmes." International Journal of Mobile and Blended Learning 9, no. 4 (2017).

Dharmawati. "Penggunaan Media E-Learning Berbasis Edmodo Dalam Pembelajaran English for Business.” Jurnal Sistem Informasi 01, no. 01 (2017).

Mediawati, Elis. "Pengaruh Motivasi Belajar Mahasiswa Dan Kompetensi Dosen Terhadap Prestasi Belajar." Jurnal Pendidikan Ekonomi Dinamika Pendidikan 5, no. 2 (2010).

Ningsih, Yunika Lestaria, Marhamah, and Misdalina. "Peningkatan Hasil Belajar Dan Kemandirian Belajar Metode Statistika Melalui Pembelajaran Blended Learning." Al-Jabar: Jurnal Pendidikan Matematika 8, no. 2 (2017).

Pima, John Marco, Michael Odetayo, Rahat Iqbal, and Eliamani Sedoyeka. "A Thematic Review of Blended Learning in Higher Education." International Journal of Mobile and Blended Learning 10, no. 1 (2018).

Prayitno, Edi, and Lusi Rachmiazasi Masduki. "Pengembangan Media Blended Learning Dengan Model Flipped Classroom Pada Mata Kuliah Pendidikan Matematika II." Jurnal Ilmiah Pendidikan Matematika 1, no. 2 (n.d.).

Setiawan, Agus. "Hubungan Kausal Penalaran Matematis Terhadap Prestasi Belajar Matematika Pada Materi Bangun Ruang Sisi Datar Ditinjau Dari Motivasi Belajar Matematika Siswa." Al-Jabar: Jurnal Pendidikan Matematika 7, no. 1 (2016).

Shen, Pei-Di, and Chia-Wen Tsai. "Exploring the Effects of Web-Enabled SelfRegulated Learning and Online Class Frequency on Students' 
Computing Skills in Blended Learning Courses." International Journal of Mobile and Blended Learning 1, no. 3 (2009).

Sumandya, I Wayan, I Gusti Putu Suharta, and Gede Suweken. "Pengembangan Pembelajaran Geometri Dimensi Tiga Berwawasan Pendidikan Matematika Realistik Berorientasi Blended Learning Dalam Upaya Meningkatkan Aktivitas Dan Hasil Belajar Matematika Siswa Kelas XI SMK." E-Journal Program Pascasarjana Universitas Pendidikan Ganesha Program Studi Matematika 2 (2013).

Taylor, Maurice, Sait Atas, and Shehzad Ghani. "Exploring the Experiences of Students and Professors in a Blended Learning Graduate Program: A Case Study of a Faculty of Education." International Journal of Mobile and Blended Learning 9, no. 1 (2017).

Untari, Erny. "Eksperimentasi Pembelajaran Kooperatif Tipe STAD Dan TPS Terhadap Prestasi Belajar Matematika Ditinjau Dari Motivasi Berprestasi." Al-Jabar : Jurnal Pendidikan Matematika 8, no. 1 (2017).

Yustinaningrum, Bettri. "The Implementation of E-Learning Web-Based Model Centric Course (Edmodo) toward The Mathematics' Interest and Learning Outcomes." Al-Jabar: Jurnal Pendidikan Matematika 9, no. 1 (2018). 